\title{
Production of depolymerized lignin resin material from lignocellulosic biomass using acetone-water binary solution
}

\section{$\operatorname{AUTHOR}(\mathrm{S})$ :}

Muranaka, Yosuke; Murata, Ryuichi; Hasegawa, Isao; Mae, Kazuhiro

\section{CITATION:}

Muranaka, Yosuke ... [et al]. Production of depolymerized lignin resin material from lignocellulosic biomass using acetone-water binary solution. Chemical Engineering Journal 2015, 274: 265-273

ISSUE DATE:

2015-08-05

URL:

http://hdl.handle.net/2433/217397

\section{RIGHT:}

(c) 2015. This manuscript version is made available under the CC-BY-NC-ND 4.0 license

http://creativecommons.org/licenses/by-nc-nd/4.0/; The full-text file will be made open to the public on 05 August 2017 in accordance with publisher's 'Terms and Conditions for Self-Archiving'.; この論文は出版社版でありません。引用の際 には出版社版をご確認ご利用ください。; This is not the published version. Please cite only the published version. 


\section{Production of depolymerized lignin resin material}

\section{from lignocellulosic biomass using acetone-water}

\section{binary solution.}

Yosuke Muranaka ${ }^{a}$, Ryuichi Murata ${ }^{a}$, Isao Hasegawa ${ }^{a^{*}}$, and Kazuhiro Mae ${ }^{a}$

${ }^{a}$ Department of chemical engineering, Kyoto University, Nishikyo-ku, Kyoto 615-8510, Japan

*Telephone: +81 75383 2678. Fax: +81 75383 2638. E-mail: hasegawa@cheme.kyotou.ac.jp

\section{ABSTRACT}

The use of lignin, one of the main components of biomass, has only been for the recovery of energy through the combustion due to its complex structure. However, it needs to be used as more valuable material to make biorefinery feasible. In this study, the development of the lignin conversion method into resin materials was examined. Lignin was extracted from biomass with acetone/water binary solution at $220{ }^{\circ} \mathrm{C}$. The extracted lignin solution was treated under the severer condition for the depolymerization using flow reaction system. Through these two-step treatment, the extracted lignin was depolymerized to $\mathrm{Mw}<1,000$ fractions, which possessed many active sites for curing. More than $76.8 \%$ of lignin were recovered as depolymerized lignin through the whole treatment. The depolymerized lignin showed a fine activity of uniform curing with 10-15 per hundred resins(phr) of hexamine at $150{ }^{\circ} \mathrm{C}$. This resinification method 
of lignin was confirmed to be adaptive to some types of biomass, despite the belonging groups such as a coniferous tree, a broadleaf tree, or herbaceous biomass. One of thus produced resins was confirmed to be the competitive resin with a conventional phenolic novolac resin.

Key words

Lignin resin, Depolymerization, Extraction, Two-step treatment

\section{Introduction}

Plant biomass conversion is a very attractive topic in all over the world, recently. This is because its feature of carbon neutrality, which refers to a well-balanced carbon cycle in nature [1-3]. Biomass utilization is mainly categorized into energy resource or material for the production of chemicals. Many studies focus on the production of bio-oil, which are very attractive as the solution for rapid increase of energy demand in the world [4-6]. However, the available amount of biomass resource in calorific value is roughly calculated as less than $10 \%$ of that of crude oil. Therefore, to utilize biomass as an alternative resource to crude oil, establishing the advantageous utilization method of biomass is essential. One of the biggest advantages of biomass resource is probably that biomass is oxygen-containing material. This is because, in conventional oil refinery, oxygen-containing chemicals are synthesized from ethylene or propylene by oxidation, which is very low selective conversion process. On the other hand, those chemicals are theoretically able to be synthesized in high selectivity from biomass by hydration, dehydration, and reduction. The production of chemicals are also advantageous to nature in the point of carbon neutrality, by stabilizing carbon as products for a period of biomass generation. It is also possible to utilize those biomass derivative products as energy resources in the end of their use, and this idea of "cascade use" of biomass is considered to be important $[7,8]$. Therefore, the objective of this study was set to be the production of chemicals from biomass resources. Biomass conversion technologies mainly belong to biochemical technology or thermochemical technology, and each technology has 
advantages and disadvantages in selectivity and productivity [9-11]. To replace oil refinery with biorefinery, the most important factor seems to be productivity, therefore, it is rational to develop the conversion technologies based on thermochemical technologies.

Plant biomass mainly consists of cellulose, hemicellulose, and lignin. Table 1 shows their contents of cedar, poplar, and switch grass as the representatives, respectively, of coniferous tree, broadleaf tree, and herbaceous biomass [12]. There are many reports about cellulose conversion, because of its clear structure and the high value of its derivative products [13-15]. There are also many reports about lignin conversion, however, it is very difficult to produce some specific chemicals selectively from lignin, because lignin is a complex and hugemolecular compound [16], and the structure is not precisely clarified. The basic constituents of lignin are considered to be three types of phenyl propanoids; $p$-coumaryl alcohol, coniferyl alcohol, and sinapyl alcohol [17-19]. Figure 1 describes the structures of these chemicals. In this study, these basic structures of lignin were focused on, and the development of effective thermochemical production methods of phenolic resin materials was examined. Xu et al. reported the possibility of the production of phenolic novolac resin materials from biomass resources [20]. For the conversion of lignin into phenolic resin materials, effective extraction and depolymerization of lignin are required. Kang et al. reported many advantages of hydrothermal extraction of lignin from plant biomass [18]. However, lignin is very watertolerant compound, and according to the report, it is hard to be extracted even to supercritical water. The use of organic solvent is known to help the extraction of lignin [21]. Organic solvent-soluble lignin, as known as organosolv lignin, is one of the most suitable types of technical lignin for further conversion, according to Azadi et al. [19]. Among the organic solvents, most previous studies examined the use of alcohols or organic acids, such as methanol, ethanol, formic acid, and acetic acid [22-26]. For example, when alcohol was used, the extraction under supercritical condition or the extraction with the addition of sodium 
hydroxide were effective [22,23]. Saito et al. studied the molecular weight distributions(MWDs) of extracted lignin by methanol in detail, and successfully obtained well-depolymerized lignin by adding $\mathrm{LiBr}$ which prevented the aggregation of depolymerized lignin [24]. When organic acid, mainly formic acid, was used, the extraction was promoted by the addition of hydrogen peroxide or mineral acids [19]. These examples were very successful, however, there were some issues of the use of additives which makes the recovery of reagents and products more difficult, and of the erosion of reactor when formic acid was used. Therefore, in this study, the use of acetone was examined. Acetone was proved to have high lignin-extraction ability in our previous study [25], and however its price is between methanol and formic acid, the boiling point is the lowest of these reagents which enables the recovery easier. After the extraction, the depolymerization of extracted lignin was examined under the severer conditions using flow reaction system. In addition, the further examination of producing resins (plastics) from extracted depolymerized lignin was conducted, and the performance of the product was evaluated by the comparison with that of conventional phenolic novolac resin. Phenolic novolac resin is a type of resin which possesses few mthylol groups, and requires additive reagents for curing, such as hexamethylenetetramine(hexamine) or triphenylphosphine(TPP).

\section{Experimental Section}

\subsection{Materials. Cedar (Cryptomeria japonica), rice straw and beech (Fagus crenata Blume),} which were purchased from Kobo Mokuyo-Daiku (Tokyo, Japan), were used as raw biomass samples. All samples were ground into particles under $150 \mu \mathrm{m}$. Organosolv lignin (SigmaAldrich Co. LLC.) and crystalline cellulose (Kao Corporation, Tokyo, Japan) were used as samples for the comparative evaluation of the performance of obtained samples through treatments. All the samples were dried in vacuo for $24 \mathrm{~h}$ at $70{ }^{\circ} \mathrm{C}$ prior to use. As an 
extraction solvent, acetone/water binary solution was prepared by mixing distilled water and acetone (assay: 99.5 \%, nacalai tesque, Kyoto, Japan). Bisphenol-A epoxy resin (SigmaAldrich) was used as an additive resin material. As the curing agents, hexamine (assay: > 99.5 \%, Kishida Chemical, Osaka, Japan) or TPP (assay: $98.0 \%$, Kishida Chemical) was used.

\subsection{Hydrothermal Extraction of Lignin from Biomass (1st treatment). All the types of} biomass were treated under the hydrothermal condition. The experiments were performed by using Swagelok (316 stainless steel) batch reactor with an internal volume of $30 \mathrm{~cm}^{3} .2 .0 \mathrm{~g}$ of biomass sample and $18 \mathrm{~g}$ of acetone/water binary solution (equivalent on weight basis) were mixed in a sealed batch reactor. The reactor vessel was plunged into an oil bath preheated to $180-240{ }^{\circ} \mathrm{C}$ for $1 \mathrm{~h}$, and then cooled in a water bath. This extraction condition was determined according to our previous report, which clarified the effective lignin-extraction by acetone/water binary solution from oil palm shell was achieved at about $200-220{ }^{\circ} \mathrm{C}$ in $1 \mathrm{~h}$ of treatment [25]. The products were filtered by suction and the residues were analyzed by thermo gravimetric analysis(TGA), CHNS elemental analysis and Fourier transform infrared(FT-IR) spectrometry. As a preparation for the following hydrothermal reactions, the filtrates were diluted to $40 \mathrm{~mL}$ with acetone aqueous solution (60 wt\%). Filtrates were also prepared according to the same method for analysis, subsequently being heated at $70{ }^{\circ} \mathrm{C}$ to evaporate acetone, and then filtered by suction. The residues were denoted as 1st-acetonesolubles and the solutions were denoted as 1st-water-solubles hereafter in this article.

\subsection{Hydrothermal Depolymerization of Extracted Lignin Solution (2nd treatment). The} prepared lignin solutions were treated under the hydrothermal conditions using the flow reaction system. The solutions were fed into the stainless steel tube with an inner diameter of $1 \mathrm{~mm}$ using the liquid chromatography pump. The tube was immersed in an oil bath 
preheated to $250-350{ }^{\circ} \mathrm{C}$ and pressure was held at $20 \mathrm{MPa}$ by the back pressure regulator. The reaction time was calculated by the inner volume of plunged channel divided by the flow rate of solution, and corrected according to the equation 1 [26], because the residence time changes with reaction temperature due to the volume change of the solution. In concrete, the flow rate in hot channel was corrected by multiplying $\rho_{\mathrm{T}} / \rho_{25^{\circ} \mathrm{C}}(\rho$ : density of the solution $\left[\mathrm{g} \cdot \mathrm{cm}^{-3}\right], T$ : temperature $\left.\left[{ }^{\circ} \mathrm{C}\right]\right)$. The product solutions were separated into acetone-soluble fraction (2nd-acetone-soluble) and water-soluble fraction (2nd-water-soluble).

$$
\rho=-1.6 \times 10^{-3} T+0.9661 \quad \text { (1) }\left(\rho: \text { Density }\left[\mathrm{g} \cdot \mathrm{cm}^{-3}\right] \quad T: \text { Temperature }\left[{ }^{\circ} \mathrm{C}\right]\right)
$$

\subsection{Resinification of Lignin. Depolymerized lignin obtained as acetone-soluble was} resinified with two different types of curing agents, hexamine and TPP. For curing with hexamine, the same amounts (on weight basis) of acetone-soluble, methanol, and acetone were mixed, and then 5, 10 or 15 phr (5-15 g/100g-resin material) of hexamine were added. For curing with TPP, the same amounts (on weight basis) of acetone-soluble, bisphenol-A epoxy resin, and acetone were mixed, and then 1 phr of TPP was added. Curing agents and samples were mixed in a glass bottle (internal volume of $50 \mathrm{~cm}^{3}$ ), and then samples were dispersed uniformly using an ultrasonic wave disperser. Dispersed samples were poured into evaporating dishes and heated at $60{ }^{\circ} \mathrm{C}$ for the evaporation of methanol and acetone, and then dried in vacuo at $60{ }^{\circ} \mathrm{C}$ for $1 \mathrm{~h}$. Thus obtained samples (the uniformly mixed acetone-solubles and curing agents) were cured on a hot plate preheated to $150{ }^{\circ} \mathrm{C}$ to examine the thermal curing properties. The thermal curing properties during resinification were visually observed and evaluated by differential thermal analysis(DTA).

2.4. Analyses of Products. Ultimate analysis of samples was performed using a CHNS elemental analyzer (BEL Japan, Inc., ECS4010). The pyrolysis profiles and the softening points 
of the solid samples were examined using a thermogravimetric analyzer (Shimadzu, TGA-50) and a thermomechanical analyzer (Shimadzu, TMA-50). All the analysis by thermogravimetric analyzer were performed at $20{ }^{\circ} \mathrm{C} / \mathrm{min}$ of the rate of temperature rising. The thermal curing properties during resinification were evaluated with a differential thermal analyzer (Shimadzu, DTA-50). The gel permeation chromatography(GPC) was used to estimate the MWDs of the lignin solution. The packed column used was Shodex Asahipak GF-310HQ (SHOWA DENKO), and an eluent of acetone was supplied at the flow rate of $0.7 \mathrm{~mL} / \mathrm{min}$ to the high performance liquid chromatography equipped with a charged aerosol detector (Dionex, Corona). The gel filtration chromatography(GFC) was used to estimate the MWDs of the water-soluble components. The packed column used is Shodex OHpak SB-802.5 (SHOWA DENKO), and an eluent of distilled water was supplied at the flow rate of $1.0 \mathrm{~mL} / \mathrm{min}$ to the high performance liquid chromatography equipped with a refractive index detector (Shimadzu, RID-10A). FT-IR spectrometers (JEOL, JIR-SPX60) were used for the evaluation of the functional groups in solid samples. The lignin contents of materials were measured by KlasonLignin method (which is described in the section 2.5.). Figure 2 is the reaction flowchart with the summary of all the performed analysis.

2.5. Klason-Lignin Method. Lignin is the most important component of biomass in this study, and the analysis of lignin contents in the samples is essential. For the analysis, Klason-Lignin method was adopted [27]. $0.3 \mathrm{~g}$ of dry biomass samples were mixed with $3 \mathrm{~mL}$ of $72 \mathrm{wt} \%$ $\mathrm{H}_{2} \mathrm{SO}_{4}$ in pressure resistant vessels, and the vessels were plunged into a water bath preheated to $30{ }^{\circ} \mathrm{C}$ for $1 \mathrm{~h}$. After an elapse of $1 \mathrm{~h}, 84 \mathrm{~mL}$ pf pure water was poured into the vessels, and another $1 \mathrm{~h}$ of heating was carried out in an oil bath preheated to $120{ }^{\circ} \mathrm{C}$. The products were filtered by suction immediately after the heating, and the filtrates were diluted to $150 \mathrm{~mL}$ by pure water, and then the residues were dried in vacuo at $60{ }^{\circ} \mathrm{C}$ for $12 \mathrm{~h}$. The weights of dry 
residues were measured as acid-insoluble lignin. The filtrates were analyzed using UV-Visible spectrophotometer (Shimadzu, UVmini-1240) for the calculation of acid-soluble lignin [28,29].

\section{Results and Discussion}

3.1. The Analyses of Biomass Materials. Plant biomass can be categorized into several groups. The selected samples in this study were cedar as a coniferous tree, beech as a broadleaf tree, and rice straw as a herbaceous biomass. The elemental compositions and lignin contents of ground biomass samples were analyzed by Klason-Lignin method and CHNS elemental analysis. The analyses are summarized in Table 2. Lignin content was the highest in cedar, reaching over $30 \mathrm{wt} \%$. Beech and rice straw contained about $25 \mathrm{wt} \%$ of lignin in total; $20 \mathrm{wt} \%$ of acid-insoluble and $5 \mathrm{wt} \%$ of acid-soluble. Comparing lignin contents with those of shown in Table 1, the agreements between the same groups of biomass were very well despite the types of plants. The elemental compositions of samples were almost the same with about $50 \mathrm{wt} \%$ of carbon contents. Rice straw, as herbaceous biomass, contained more ashes than woody biomass. Figure 3 shows the pyrolysis profiles of ground samples analyzed by TGA. The decomposition temperature, which is the point the weight change begin, was lower for rice straw $\left(180-220{ }^{\circ} \mathrm{C}\right)$ than woody biomass samples $(240$ $280{ }^{\circ} \mathrm{C}$ ) and the yields of char, which are the yield at $900{ }^{\circ} \mathrm{C}$, were almost the same, about 0.2 g/(g-dry ash free) for cedar and rice straw.

\subsection{Extraction of Lignin from Biomass (1st treatment).}

3.2.1. Determination of 1st Treatment Temperature. Cedar was treated with acetone/water binary solution at the sample concentration of $10 \mathrm{wt} \%$ for $1 \mathrm{~h}$ to determine the optimum temperature for the extraction of lignin. Through this treatment, lignin and hemicellulose were expected to be extracted as solution, and cellulose was expected to be collected as 
residue. The residues recovered after the treatments were about $80 \mathrm{wt} \%$ for the treatments at 180-200 ${ }^{\circ} \mathrm{C}$, and about $60 \mathrm{wt} \%$ for the treatments at $220-240{ }^{\circ} \mathrm{C}$. As shown in Table 2, lignin content of cedar was $33.2 \mathrm{wt} \%$, which means the temperature under $200{ }^{\circ} \mathrm{C}$ was not high enough for the extraction, leaving some lignin un-extracted. On the other hand, more than $33.2 \%$ were converted into soluble components through the treatment at over $200{ }^{\circ} \mathrm{C}$. The reaction temperature for the 1 st treatment was thus determined as $220{ }^{\circ} \mathrm{C}$.

3.2.2. The Analysis of 1st-Acetone-Soluble. 1st-acetone-solubles were desirable to consist of extracted lignin. The elemental compositions of 1st-acetone-solubles are shown in Table 2, with that of organosolv lignin for comparison. All the analyses were similar, with little ash contents. Figure 4 shows the pyrolysis profiles of 1st-acetone-solubles measured by TGA. The pyrolysis profiles of organosolv lignin and crystalline cellulose are also shown in the graph. All 1st-acetone-solubles drew the similar curves to that of organosolv lignin, in the points of the decomposition temperature and the yield of char. All analyses of the elemental compositions and the pyrolysis profiles indicated that the 1st-acetone-solubles from all types of biomass mainly consisted of lignin. The recovery yields as 1st-acetone-solubles were about $30 \mathrm{wt} \%$ for all the samples, indicating that lignin were extracted almost completely as 1st-acetone-solubles by the 1 st treatment.

3.2.3. The Analysis of Residue. Residues were desirable to consist of cellulose. The pyrolysis profiles and the elemental compositions of obtained residues were analyzed by TGA and CHNS elemental analysis, respectively. The pyrolysis profiles are shown in Figure 5, and the elemental compositions are listed in Table 2. The pyrolysis profiles of all the residues were desirably similar to that of crystalline cellulose, but not to that of organosolv lignin (Figure 5). In addition, the elemental compositions of most of the residues were also similar to that of crystalline cellulose (Table 2), which indicated that the residues from 1st treatment mainly 
consisted of cellulose. To confirm this, the residues and cellulose were analyzed by FT-IR sprctrometry, and Figure 6 shows the FT-IR spectra of the samples. All the residues and cellulose showed very similar FT-IR spectra, therefore, the residues were confirmed to consist mainly of cellulose. Although only the residue from cedar showed a little higher carbon content according to Table 2, it was reasonable considering that the recovery yield of 1st-acetone-soluble was lower only for cedar sample, which meant some amounts of lignin remained un-extracted from cedar.

\subsubsection{The Conversion after 1st Treatment. The conversions after 1st treatment are} summarized in Table 3 on the basis of initial sample weight. The total yields of residue, 1stacetone-soluble, and 1st-water-soluble are the total recovery yields after 1st treatment. The yield for each sample was less than $100 \mathrm{wt} \%$, probably because of the loss through the first treatment as volatile components. The yield of residue was higher for cedar sample, which is due to the high cellulose content of coniferous tree (Table 1) and some amounts of unextracted lignin. Rice straw produced larger amounts of residues than cellulose content of switch grass, however, they derive from the considerable amounts of ashes as shown in Table 2. About beech, the amounts of residues showed the agreement with cellulose content of poplar. In summary, most of lignin were successfully extracted as 1st-acetone-solubles, and most of cellulose were recovered as residues by the 1st treatment regardless of the types of biomass.

3.3. Depolymerization of Extracted Lignin (2nd Treatment). The filtrate of 1st treatment (the mixture of 1st-acetone-soluble and 1st-water-soluble) was treated under the hydrothermal condition using a flow reactor for the depolymerization of soluble fractions.

\subsubsection{Determination of 2nd Treatment Condition. To determine the optimum reaction} condition for the 2nd treatment, the hydrothermal treatments (2nd treatments) on the filtrate 
of 1st treatment of cedar under the several conditions were conducted. Figure 7 (a) shows the MWDs of products analyzed by GPC. The notes in the graph represent temperature-time of 2nd treatment. Considering that MWDs for phenolic resin materials are generally 500-800, it is preferable to depolymerize soluble fractions to $\mathrm{Mw}<1,000$ (about 7 phenol units). Some fractions of $\mathrm{Mw}>1,000$ were recognized in the sample treated at $250{ }^{\circ} \mathrm{C}$. Figure 7 (b) shows the contents of samples obtained by the treatments over $300{ }^{\circ} \mathrm{C}$. Judging from the results, the solution treated at $300{ }^{\circ} \mathrm{C}$ for 8.3 min consisted of pure $(>98 \%) \mathrm{Mw}<1,000$ fractions, and yielded $0.72 \mathrm{~g} /\left(\mathrm{g}-1 \mathrm{st}\right.$ filtrate), therefore, the condition of $300{ }^{\circ} \mathrm{C}$ and $8.3 \mathrm{~min}$ was determined as the optimum condition for the 2nd treatment.

\subsubsection{The Conversion after 2 nd Treatment. The conversions after 2 nd treatment are}

summarized in Table 3 on the basis of initial sample weight. The total yields of residue, 2ndacetone-soluble, and 2nd-water-soluble are the total recovery yields after 2nd treatment. Depolymerized lignin was desirable to be contained in 2nd-acetone-soluble, and the yield of 2nd-acetone-soluble was different for each sample, ranging 22.3-36.4 wt\%. Some amounts of 1st-acetone-soluble of cedar were converted into water-soluble components, however, there was little loss in total yield through the 2nd treatment. Rice straw decreased the yield of soluble components by the 2nd treatment, which was because some of them were converted into volatile components. The yields of acetone-soluble components of cedar and rice straw decreased through the 2nd treatment, however, still about $80 \mathrm{wt} \%$ of lignin in materials were recovered. About beech, on the other hand, the yield of acetone-soluble component increased by the 2nd treatment, decreasing the yield of water-soluble component. 2nd-acetone-soluble of beech was obtained by the yield of $140 \mathrm{wt} \%$ of lignin in material, which meant it contained some hemicellulose derivatives. Although the decrease of the yield of acetone-soluble (which means the decrease the yield of lignin) is one of the issues of 2nd treatment, and it was not 
observed for beech sample, there is a need of investigation whether the hemicellulose derivatives have any effects as inhibitors on the resinification.

3.3.3. The Analysis of 2nd-Acetone-Soluble. 2nd-acetone-solubles were analyzed by TGA, CHNS elemental analysis, thermomechanical analysis(TMA) and GPC. Figure 8 shows the pyrolysis profiles of samples analyzed by TGA. All the profiles were very similar to that of organosolv lignin. 2nd-acetone-solubles of cedar and rice straw decreased the yields of char closer to that of organosolv lignin by the 2nd treatment comparing with those of 1st-acetonesolubles, which meant acetone-solubles were converted into lignin-purer components by the 2nd treatment. 2nd-acetone-soluble of beech lowered its decomposition temperature. Among the main components of biomass, hemicellulose shows the lowest decomposition temperature (about $180{ }^{\circ} \mathrm{C}$ ) and lignin shows the highest decomposition temperature (about $280{ }^{\circ} \mathrm{C}$ ), which confirms the assumption discussed in the previous section that some of 1st-watersolubles (hemicellulose derivatives) of beech were converted into acetone-soluble components by the 2nd treatment. The elemental compositions of samples were analyzed by CHNS elemental analysis, and the results are shown in Table 2. All the samples increased carbon contents and decreased oxygen contents from 1st-acetone-solubles. Oxygen content is generally estimated to increase by hydrolysis, however, the carbonation at high temperature had a bigger effect in this reaction. About ash, all the samples contained none of that anymore after the 2nd treatment. Next, the softening temperatures of samples were measured by TMA. The results are listed in Table 4. The softening temperatures of 1st-acetone-solubles of all samples were very different, and high in order from cedar, beech, to rice straw. This difference was because of the difference in constituents of lignin, and the hemicellulose derivative in 1st-acetone-solubles. All the samples lowered the softening temperatures remarkably by the 2nd treatment, which indicated that extracted lignin was depolymerized well. To confirm this, the MWDs of 2nd-acetone-solubles were analyzed by GPC. The results 
are shown in Figure 9 with those of 1st-acetone-solubles. The black solid lines and the gray broken lines are, respectively, for 2nd-acetone-solubles and 1st-acetone-solubles. The base lines were shifted for each type of biomass sample. For the relative evaluation by the intensity, $10 \mathrm{mg}$ of each acetone-soluble was dissolved in $5 \mathrm{~mL}$ of acetone before the analysis. All the samples increased the intensity of the lower molecular weight fractions of $\mathrm{Mw}<1,000$ by the 2 nd treatment. The peaks of the fractions of $\mathrm{Mw}>1,000$ of 1 st-acetonesolubles of cedar and rice straw were shifted to lower molecular weight area. 1st-acetonesoluble of beech, different from the other samples, did not have peaks of the higher molecular weight fraction. This was probably because acetone-soluble was actually obtained as "waterinsoluble components” in this experimental method, and 1st-acetone-soluble of beech could not be completely dissolved in acetone before the analysis by GPC. Some insoluble fractions were actually recognized in the solution of 1st-acetone-soluble of beech, which supported this assumption. Those insoluble fractions were depolymerized by the 2nd treatment and, converted into acetone-soluble components. As a summary, the acetone-soluble components of all the types of biomass were converted into depolymerized lignin of $\mathrm{Mw}<1,000$ fractions by the 2 nd treatment.

3.3.4. The Analysis of Water-Soluble Components. Water-solubles were desirable to consist of hemicellulose derivatives. 1st- and 2nd-water-solubles were analyzed by GFC. Figure 10 shows the MWDs of all the water-solubles. Because the concentrations of samples were not modulated, the intensity was standardized by the strongest values for each sample. The black solid lines are for 2nd-water-solubles, whereas the black broken lines are for 1st-warersolubles. The gray dotted vertical lines in the graph indicate the retention time of xylose, glucose and cellobiose, respectively from the left. Because the lower molecular weight compounds tend to have peaks at later retention time, the horizontal axes were expressed in 
the other way around. All the water-solubles did not contain monosaccharides such as glucose or xylose, but consisted of bigger saccharides than cellobiose.

3.3.5. The Mitigation of Reaction Conditions for 2nd Treatment of Rice Straw. As mentioned in the previous section and shown in Table 3, there were the huge decreases of the yield of acetone-soluble and the total yields of rice straw derivatives through the 2nd treatment, which were not desirable. Therefore, the 2nd treatment of rice straw derivative was conducted under the milder condition of $275{ }^{\circ} \mathrm{C}$ and $9.0 \mathrm{~min}$. The yields of 2nd-acetone-soluble and 2ndwater-soluble were very similar to those obtained by the reaction at $300{ }^{\circ} \mathrm{C}$ for $8.3 \mathrm{~min}$. However, the MWDs were different with many undepolymerized fractions of Mw $>1,000$ remaining. These facts meant that the milder reaction did not improve the yield, and was not severe enough for the depolymerization of lignin.

\subsubsection{Summary of 2nd Treatment. The extracted lignin through 1st treatment were} depolymerized to $\mathrm{Mw}<1,000$ fractions in high yields by the 2nd treatment. The results were obtained from all the types of biomass samples used in this study. The depolymerized lignin showed low softening temperature, which is essential for the use as resin material. Next, in the following section, the resinification profile of depolymerized lignin was examined.

\subsection{Resinification of Extracted Depolymerized Lignin.}

\subsubsection{Resinification of Lignin Using Hexamine as the Curing Agent. Extracted lignin} obtained as acetone-solubles were resinified using hexamine as the curing agent. The curing profiles were observed visually and evaluated by DTA. At first, to make a standard, the curing behaviour of phenolic novolac resin (obtained from the resin production company, Sumitomo Bakelite Co., Ltd. Tokyo, Japan) mixed with 10 phr of hexamine was observed visually. The mixed sample was cured by heat on the hot plate preheated to $150{ }^{\circ} \mathrm{C}$. The 
powder sample started melting immediately on the hot plate, and melted completely after $30 \mathrm{~s}$ of heating. Some voids, which appeared because the discharged gas during curing were trapped in a resin, were generated partly after 3 min of heating, and then they were generated in all the parts of sample in another $1 \mathrm{~min}$. Although voids are undesirable matter in usual manufactural process, they were considered as the signs of rsinification in this study. Consequently, the resinification time for phenolic novolac resin at $150{ }^{\circ} \mathrm{C}$ was determined as 3-4 min. Next, all the acetone-solubles were heated with $10 \mathrm{phr}$ of hexamine. 1st-acetonesolubles did not melt well with most parts staying as powder-shaped, and none of them were cured uniformly. The softening temperature for 1 st-acetone-soluble of cedar was $92.0{ }^{\circ} \mathrm{C}$ according to Table 4, which was lower enough than $150{ }^{\circ} \mathrm{C}$, however, probably added hexamine rose the softening temperature. On the other hand, 2nd-acetone-solubles started melting immediately when they were put on the hot plate, and they were resinified uniformly after 4-5 min of heating. These observed curing behaviours were very similar to that of phenolic novolac resin. Comparing the softening temperature of samples, 2nd-acetonesoluble of cedar showed higher softening temperature than 1st-acetone-soluble of rice straw. However, 2nd-acetone-soluble of cedar apparently showed more preferable curing behaviour in terms of uniform resinification. To confirm the thermal durability of resinified 2ndacetone-soluble of cedar, it was examined by TGA. The decomposition temperature was higher than that of organosolv lignin, and the produced amount of char at $900{ }^{\circ} \mathrm{C}$ was 1.5 times more than that from olganosolv lignin, which meant that the thermal durability improved after curing by forming cross-linking. These facts indicated the key for the production of functional lignin resin was not just lowering the softening temperature of lignin, but the depolymerization to $\mathrm{Mw}<1,000$ fractions. To examine the curing profiles quantitatively, thermal curing properties during resinification were evaluated by DTA at a heating rate of $10 \mathrm{~K} / \mathrm{min}$ in a nitrogen flow of $50 \mathrm{~mL} / \mathrm{min}$. Through the DTA, the exothermic 
energy was measured. The higher exothermic energy indicate the better curing activity, because the energy is discharged when samples form the cross-linking, which means the curing reaction. To begin with, 2nd-acetone-soluble of cedar was analyzed with 0, 5, 10, 15 phr of hexamine. The exothermic energies measured by the analyses were 37.6, 76.5, 81.2 $\mathrm{J} / \mathrm{g}$, respectively when $5,10,15 \mathrm{phr}$ of hexamine were added. Because the exothermic energies and the profiles analyzed by DTA during the resinification with 10 or $15 \mathrm{phr}$ of hexamine were similar, and produced higher energy than with $5 \mathrm{phr}$ of hexamine, the other samples were examined with 10 phr of hexamine. Figure 11 shows the DTA profiles, which expresses the positive charge flow when curing reaction occurs. Table 5 summarizes the results of exothermic energies, the ranges of curing temperature, and the peak curing temperatures measured by DTA. All the samples showed the peak temperatures at 140$170{ }^{\circ} \mathrm{C}$. The peak temperature for 2 nd-acetone-soluble of cedar was $162{ }^{\circ} \mathrm{C}$, which was higher than the other types of biomass samples. However, this was considered as unimportant matter, because all the 2nd-acetone-solubles including cedar derivative were resinified at $150{ }^{\circ} \mathrm{C}$ of heating in 4-5 min anyway. The exothermic energies during the resinification were higher for 2nd-acetone-solubles than 1st-acetone-solubles of all the types of biomass, which meant that the amounts of active sites of samples were increased by the depolymerization. As the final evaluation in this section, the mechanical durability of produced resin from 2ndacetone-soluble of cedar was examined. This examination was performed by pressing the lamination layer of resin-supported paper, and the pressure at which the lamination layer was bent was measured. This is a major examination method in resin companies, and the examination was performed by resin production company, Sumitomo Bakelite. As the result, the mechanical durability was competitive with a conventional fossil derivative phenolic novolac resin (the measured pressure at the bending point; $172 \mathrm{MPa}$ for phenolic novolac resin, $164 \mathrm{MPa}$ for produced resin), and satisfied the Japanese Industrial Standard [30]. Even 
though the mechanical durability was examined only for 2nd-acetone-soluble of cedar, the other analyses indicated that 2nd-scetone-solubles of beech and rice straw could also be adapted to the available resin materials.

\subsubsection{Resinification of Cedar Derivative Lignin with Bisphenol-A Epoxy Resin Using TPP} as the Curing Agent. The mixtures of 1st- or 2nd-acetone-soluble of cedar and bisphenol-A epoxy resin were resinified using TPP as the curing agent. The curing profiles were observed visually and evaluated by DTA. To observe the curing behaviours of samples visually, samples were cured by heat on the hot plate preheated to $150{ }^{\circ} \mathrm{C}$. The samples were viscous under the room temperature because bisphenol-A epoxy resin was liquid resin material with low softening temperature. Both 1st-acetone-soluble and 2nd-acetone-soluble samples started melting immediately on the hot plate, and they were cured uniformly in 3-5 min. This meant when the samples were mixed with bisphenol-A epoxy resin, even 1st-acetone-soluble, which was just the extracted lignin, was able to be resinified under the relatively low temperature. The decomposition temperatures of cured samples measured by TGA were $350-400{ }^{\circ} \mathrm{C}$. These were much higher comparing with that of the mixture sample of organosolv lignin and bisphenol-A epoxy resin, which meant that the thermal durability were better for the extracted lignin by proposed method than for the purchased olganosolv lignin. To examine the curing profiles quantitatively, thermal curing properties of the lignin samples during resinification were examined by DTA. The curing temperature and the exothermic energy for 1st-acetone-soluble were $162.5{ }^{\circ} \mathrm{C}$ and $42.0 \mathrm{~J} / \mathrm{g}$, which were $176.0{ }^{\circ} \mathrm{C}$ and $55.5 \mathrm{~J} / \mathrm{g}$ for $2 \mathrm{nd}$ acetone-soluble. As assumed that 2nd-acetone-soluble possessed more active sites for the curing than 1st-acetone-soluble, 2nd-acetone-soluble produced more exothermic energy. However, the difference of exothermic energy between 1st-acetone-soluble and 2nd-acetonesoluble was less comparing with hexamine-added samples. In addition, the curing 
temperature of 1st-acetone-soluble was even lower than that of 2nd-acetone-soluble. Judging from these analyses and visual observation, resinification of lignin with bisphenol-A epoxy resin and TPP does not require the depolymerization by the 2nd treatment.

3.4.3. Summary of Resinification. Although all the 1st-acetone-solubles showed the curing activities when they were heated with hexamine, they mainly consisted of high molecular weight components with high curing temperatures, therefore, they were not cured uniformly. 2nd-acetone-solubles, on the other hand, mainly consisted of low molecular weight components with many active sites and low curing temperatures, which led to the production of uniformly cured available resin. The amounts of hexamine required for the effective resinification were clarified to be 10-15 phr. Thus produced resins were analyzed by several methods, and indicated to be a competitive product with conventional phenolic novolac resin. In addition, the potential of extracted lignin as partly alternative to the conventional fossil derivative resin material, bisphenol-A, was indicated.

\section{Conclusion}

The potential of extracted lignin as resin material was examined. Lignin was extracted from biomass with acetone/water binary solution at $220{ }^{\circ} \mathrm{C}$. The extracted lignin solutions were treated under the hydrothermal condition at $300{ }^{\circ} \mathrm{C}$ for 8.3 min under the pressure of $20 \mathrm{MPa}$. By the hydrothermal treatment, the extracted lignin was depolymerized to $\mathrm{Mw}<1,000$ fractions, which possessed many active sites for curing. The yields of depolymerized lignin were over $76.8 \mathrm{wt} \%$ on the basis of lignin content in the biomass materials. Produced depolymerized lignin showed fine activity of uniform curing with small amounts of hexamine at $150{ }^{\circ} \mathrm{C}$. Thus produced resin from cedar was revealed to be a competitive resin with conventional phenolic novolac resin. The produced resin from beech and rice straw were also indicated to be a competitive available resin by some analyses. 
Table 1. Components of Woody Biomass from Some Different Types

\begin{tabular}{lcccc}
\hline Sample & Cellulose & $\begin{array}{c}\text { Hemicellulose } \\
\text { [wt\% d.b.] }\end{array}$ & Ash \\
\hline Cedar & 52.2 & 13.7 & 33.2 & 0.9 \\
Poplar & 41.3 & 32.9 & 25.6 & 0.2 \\
Switch grass & 32.0 & 18.1 & 25.2 & 24.7 \\
\hline
\end{tabular}

Table 2. Ultimate Analyses of Samples

\begin{tabular}{|c|c|c|c|c|c|c|c|}
\hline \multicolumn{2}{|l|}{ Sample } & \multicolumn{4}{|c|}{ [wt\% d.a.f.] } & $\begin{array}{c}\text { Ash } \\
\text { [wt\% d.b.] }\end{array}$ & $\begin{array}{c}\text { Lignin } \\
\text { [wt\% d.b.] }\end{array}$ \\
\hline \multicolumn{2}{|l|}{ Cedar } & 53.1 & 6.7 & 0.1 & 40.1 & 3.4 & 33.2 \\
\hline \multicolumn{2}{|l|}{ Beech } & 50.6 & 6.6 & 0.2 & 42.6 & 1.8 & 25.8 \\
\hline \multicolumn{2}{|c|}{ Rice straw } & 49.7 & 6.9 & 0.6 & 42.8 & 14.5 & 25.6 \\
\hline \multicolumn{2}{|c|}{ Organosolv lignin } & 68.0 & 5.8 & 0.0 & 26.2 & & \\
\hline \multicolumn{2}{|c|}{ Cellulose } & 44.4 & 6.2 & 0.0 & 49.3 & & \\
\hline \multirow{3}{*}{$\begin{array}{l}\text { 1st- } \\
\text { Residue }\end{array}$} & Cedar & 53.5 & 6.8 & 0.0 & 39.7 & 8.8 & \\
\hline & Beech & 45.0 & 5.3 & 0.0 & 49.7 & 5.2 & \\
\hline & Rice straw & 42.9 & 5.2 & 0.1 & 51.9 & 25.6 & \\
\hline \multirow{3}{*}{$\begin{array}{l}\text { 1st- } \\
\text { Acetone- } \\
\text { soluble }\end{array}$} & Cedar & 68.0 & 5.2 & 0.3 & 26.5 & 1.8 & \\
\hline & Beech & 65.8 & 5.4 & 0.2 & 28.6 & 0.0 & \\
\hline & Rice straw & 67.6 & 5.9 & 0.6 & 25.9 & 1.8 & \\
\hline \multirow{3}{*}{$\begin{array}{l}\text { 2nd- } \\
\text { Acetone- } \\
\text { soluble }\end{array}$} & Cedar & 72.4 & 5.3 & 0.2 & 22.1 & 0.0 & \\
\hline & Beech & 67.4 & 6.0 & 0.4 & 26.1 & 0.0 & \\
\hline & Rice straw & 70.1 & 6.4 & 1.2 & 22.3 & 0.0 & \\
\hline
\end{tabular}

Table 3. Yield of Each Component

\begin{tabular}{lccc}
\hline Sample & Cedar & $\begin{array}{c}\text { Beech } \\
{[\mathrm{wt} \%]}\end{array}$ & Rice straw \\
\hline Residue & 55.2 & 41.5 & 41.3 \\
1st-Acetone-soluble & 31.7 & 33.5 & 28.9 \\
1st-Water-soluble & 5.2 & 11.6 & 18.8 \\
2nd-Acetone-soluble & 25.5 & 36.4 & 22.3 \\
2nd-Water-soluble & 10.1 & 4.6 & 15.8 \\
\hline
\end{tabular}

Table 4. The Softening Temperatures of Acetone-Solubles Measured by TMA $\left(10^{\circ} \mathrm{C} / \mathrm{min}\right)$ 


\begin{tabular}{lccc}
\hline Sample & Cedar & $\begin{array}{c}\text { Beech } \\
{\left[{ }^{\circ} \mathrm{C}\right]}\end{array}$ & Rice straw \\
\hline 1st-Acetone-soluble & 92.0 & 82.6 & 65.3 \\
2nd-Acetone-soluble & 70.1 & 53.4 & 51.9 \\
\hline
\end{tabular}

Table 5. Exothermic Energies, The Ranges of Curing Temperature, and The Peak Curing Temperatures of Acetone-Solubles During The Resinification Procedure Measured by DTA

\begin{tabular}{llccc}
\hline Sample & & $\begin{array}{c}\text { Exothermic } \\
\text { energy } \\
{[\mathrm{J} / \mathrm{g}]}\end{array}$ & $\begin{array}{c}\text { Range of curing } \\
\text { temperature } \\
{\left[{ }^{\circ} \mathrm{C}\right]}\end{array}$ & $\begin{array}{c}\text { Peak curing } \\
\text { temperature } \\
{\left[{ }^{\circ} \mathrm{C}\right]}\end{array}$ \\
\hline 1st- & Cedar & 42.5 & $130-170$ & 162 \\
Acetone- & Beech & 78.3 & $129-163$ & 153 \\
soluble & Rice straw & 43.5 & $131-172$ & 144 \\
\hline 2nd- & Cedar & 76.5 & $138-182$ & 154 \\
Acetone- & Beech & 87.7 & $129-169$ & 145 \\
soluble & Rice straw & 80.5 & $124-168$ & 155 \\
\hline
\end{tabular}

Figure 1. The basic constituents of lignin (a) p-coumaryl alcohol, (b) coniferyl alcohol, (c) sinapyl alcohol.

Figure 2. Reaction flowchart and performed analysis.

Figure 3. Decomposition profiles of the raw materials measured by TGA.

Figure 4. Decomposition profiles of 1st-acetone-solubles measured by TGA.

Figure 5. Decomposition profiles of the residues measured by TGA.

Figure 6. FT-IR spectra of residues.

Figure 7. (a) Changes in MWDs of the product solutions through the 2nd treatment (Notes; Reaction temperature - Reaction time of 2nd treatment). (b) The contents of over/under Mw $=1,000$ fractions obtained by the 2 nd treatment over $300{ }^{\circ} \mathrm{C}$ (Yield; on the basis of filtrate of 1st treatment). 
Figure 8. Decomposition profiles of 2nd-acetone-solubles measured by TGA.

Figure 9. Changes in MWDs of acetone-solubles.

Figure 10. Changes in MWDs of water-solubles (The vertical dotted lines stand for the retention times of xylose, glucose and cellobiose from the left).

Figure 11. Differential thermal analyses during curing reaction of acetone-solubles (Black lines; 2nd-acetone-solubles, Gray lines; 1st-acetone-solubles, Solid lines; cedar, Dotted lines; beech, Broken lines; rice straw).

\section{ACKNOWLEDGMENT}

This work was financially supported by the Ministry of Education, Culture, Sports, Science and Technology of Japan through a Grant-in-Aid for Scientific Research (A) (Grant 25249109). This work was also supported by the courtesy of Sumitomo Bakelite Co., Ltd.

\section{REFERENCES}

[1] E.F. Iliopoulou, E.V. Antonakou, S.A. Karakoulia, I.A. Vasalos, A.A. Lappas, K.S. Triantafyllidis, Catalytic conversion of biomass pyrolysis products by mesoporous materials: Effect of steam stability and acidity of Al-MCM-41 catalysts, Chemical Engineering Journal 134 (2007) 51-57.

[2] H.L. Chum, R.P. Overend, Biomass and renewable fuels, Fuel Processing Technology 71 (2001) 187-195.

[3] N.Z. Muradov, T.N. Veziroğlu, “Green” path from fossil-based to hydrogen economy: An overview of carbon-neutral technologies, International Journal of Hydrogen Energy 33 (2008) 6804-6839. 
[4] A. Ochoa, B. Aramburu, M. Ibáñez, B. Valle, J. Bilbao, A. G. Gayubo, P. Castaño, Compositional Insights and Valorization Pathways for Carbonaceous Material Deposited During Bio-Oil Thermal Treatment, ChemSusChem 7 (2014) 2597-2608.

[5] H.J. Park, J.I. Dong, J.K. Jeon, Y.K. Park, K.S. Yoo, S.S. Kim, J. Kim, S. Kim, Effects of the operating parameters on the production of bio-oil in the fast pyrolysis of Japanese larch, Chemical Engineering Journal 143 (2008) 124-132.

[6] A.V. Bridgwater, Renewable fuels and chemicals by thermal processing of biomass, Chemical Engineering Journal 91 (2003) 87-102.

[7] R. Sathre, L. Gustavsson, Energy and carbon balances of wood cascade chains, Resources, Conservation and Recycling 47 (2006) 332-355.

[8] T. Sirkin, M. ten Houten, The Cascade Chain A Theory and Tool for Achieving Resource Sustainability with Applications for Product Design, Resources, Conservation and Recycling 10 (1994) 213-277.

[9] M.E. Alzate, R. Muñoz, F. Rogalla, F. Fdz-Polanco, S.I. Pérez-Elvira, Biochemical methane potential of microalgae biomass after lipid extraction, Chemical Engineering Journal 243 (2014) 405-410.

[10] L.C. Ferreira, P.J. Nilsen, F. Fdz-Polanco, S.I. Pérez-Elvira, Biomethane potential of wheat straw: Influence of particle size, water impregnation and thermal hydrolysis, Chemical Engineering Journal 242 (2014) 254-259.

[11] D. Hernández, B. Riaño, M. Coca, M.C. García-González, Saccharification of carbohydrates in microalgal biomass by physical, chemical and enzymatic pre-treatment as a previous step for bioethanol production, Chemical Engineering Journal 262 (2015) 939-945. [12] C.N. Hamelinck, G. van Hooijdonk, A.P.C. Faaij, Ethanol from lignocellulosic biomass: techno-economic performance in short-, middle- and ling-term, Biomass and Bioenergy 28 (2005) 384-410. 
[13] S. Morales-delaRosa, J.M. Campos-Martin, J.L.G. Fierro, High glucose yields from the hydrolysis of cellulose dissolved in ionic liquids, Chemical Engineering Journal 181-182 (2012) 538-541.

[14] Y. Zhao, H.T. Wang, W.J. Lu, H. Wang, Combined supercritical and subcritical conversion of cellulose for fermentable hexose production in a flow reaction system, Chemical Engineering Journal 166 (2011) 868-872.

[15] C. Luo, S. Wang, H. Liu, Cellulose Conversion into Polyols Catalyzed by Reversibly Formed Acids and Supported Ruthenium Clusters in Hot Water, Angewandte Chemie International Edition 46 (2007) 7636-7639.

[16] H. Nimz, Beech Lignin - Proposal of a Constitutional Scheme, Angewandte Chemie International Edition 13 (1974) 313-321.

[17] T. Higuchi, Lignin biochemistry: Biosynthesis and biodegradation, Wood Science and Technology 24 (1990) 23-63.

[18] S. Kang, X. Li, J. Fan, J. Chang, Hydrothermal conversion of lignin: A review, Renewable and Sustainable Energy Reviews 27 (2013) 546-558.

[19] P. Azadi, O.R. Inderwildi, R. Farnood, D.A. King, Liquid fuels, hydrogen and chemicals from lignin: A critical review, Renewable and Sustainable Energy Reviews 21 (2013) 506-523. [20] J. Xu, J. Jiang, W. Lu, W. Dai, Y. Sun, Rice husk bio-oil upgrading by means of phase separation and the production of esters from the water phase, and novolac resins from the insoluble phase, Biomass and Bioenergy 34 (2010) 1059-1063.

[21] Q. Lu, W. Liu, L. Yang, Y. Zu, B. Zu, M. Zhu, Y. Zhang, X. Zhang, R. Zhang, Z. Sun, J. Huang, X. Zhang, W. Li, Investigation of the effects of different organosolv pulping methods on antioxidant capacity and extraction efficiency of lignin, Food Chemistry 131 (2012) 313317. 
[22] J.Y. Kim, S. Oh, H. Hwang, T. Cho, I.G. Choi, J.W. Choi, Effects of various reaction parameters on solvolytical depolymerization of lignin in sub- and supercritical ethanol, Chemosphere 93 (2013) 1755-1764.

[23] J.E. Miller, L. Evans, A. Littlewolf, D.E. Trudell, Batch microreactor studies of lignin and lignin model compound depolymerization by bases in alcohol solvents, Fuel 78 (1999) 13631366.

[24] T. Saito, J.H. Perkins, F. Vautard, H.M. Meyer, J.M. Messman, B. Tolnai, A.K. Naskar, Methanol Fractionation of Softwood Kraft Lignin: Impact on the Lignin Properties, ChemSusChem 7 (2014) 221-228.

[25] I. Hasegawa, K. Tabata, O. Okuma, K. Mae, New Pretreatment Methods Combining a Hot Water Treatment and Water/Acetone Extraction for Thermo-Chemical Conversion of Biomass, Energy \& Fuels 18 (2004) 755-760.

[26] M. Bicker, J. Hirth, H. Vogel, Dehydration of fructose to 5-hydroxymethylfurfural in suband supercritical acetone, Green Chemistry 5 (2003) 280-284.

[27] K.A. Jung, S.H. Woo, S.R. Lim, J.M. Park, Pyrolytic production of phenolic compounds from the lignin residues of bioethanol processes, Chemical Engineering Journal 259 (2015) 107-116.

[28] A.J. Stamm, J. Semb, E.E. Harris, Absorption spectra of lignin solutions, The Journal of Physical Chemistry 36 (1932) 1574-1584.

[29] A. Bailey, Ultraviolet Absorption Spectra of Chromatographic Fractions of Lignins, Journal of the American Chemical Society 73 (1951) 2325-2326.

[30] K. Mae, Japan patent JP2013-35970 (2013). 